\title{
Movimentação dentária experimental em murinos: período de observação e plano dos cortes microscópicos*
}

Ana Carolina Cuzzuol Fracalossi**, Milton Santamaria Jr ${ }^{\star \star \star}$, Maria Fernanda Martins-Ortiz Consolaro ${ }^{\star \star \star \star}$, Alberto Consolaro

\section{Resumo}

Objetivo: este trabalho tem por finalidade explicitar aspectos microscópicos relevantes da movimentação dentária induzida em murinos quanto aos: (1) diferentes períodos de observação e (2) planos dos cortes microscópicos transversais e longitudinais. Os estudos experimentais sobre a movimentação dentária induzida em murinos variam quanto aos períodos e planos de cortes microscópicos, mesmo os trabalhos que utilizam especificamente o modelo de Heller e Nanda, de 1979. Para contribuir (1) na escolha do melhor design experimental de movimentação dentária induzida em murinos em futuros trabalhos, e (2) no aperfeiçoamento dos critérios de análise por outros pesquisadores, propusemo-nos a publicar este artigo. Métodos: Empregaram-se 50 ratos machos Wistar, com 90 dias de vida, submetidos à movimentação dentária induzida por períodos de 3, 5, 7 e 9 dias. Utilizou-se movimento de inclinação mesial no primeiro molar superior esquerdo, com uma força equivalente a $75 \mathrm{cN}$. A análise microscópica qualitativa avaliou os fenômenos teciduais e celulares decorrentes da movimentação dentária induzida, nos diferentes períodos de observação e entre os cortes microscópicos transversais e longitudinais. Resultados: dos fenômenos observados, as áreas hialinas tiveram expressão máxima no período de 5 dias e as reabsorções radiculares apresentaram-se exuberantes e bem demarcadas no período de 9 dias. Nos dois fenômenos, as raízes mais afetadas foram as distais, especialmente a raiz distovestibular. Conclusão: mediante o delineamento proposto, pode-se sugerir, para futuros trabalhos nesta linha de pesquisa, períodos de análise de 5 a 9 dias e cortes microscópicos transversais.

Palavras-chave: Movimentação dentária induzida. Reabsorção óssea. Reabsorção radicular.

* Resumo da Dissertação de Mestrado apresentada à FOB-USP, Bauru, 2007.

\footnotetext{
** Mestre em Patologia Bucal pela FOB-USP. Doutoranda em Patologia na Escola Paulista de Medicina - Universidade Federal de São Paulo. *** Mestre em Ortodontia pela UFRJ. Doutorando em Patologia Bucal na Universidade Federal de São Paulo.

**** Doutora, cirurgiã-dentista em clínica privada

$\star \star \star \star \star$ Professor titular em Patologia na FOB-USP.
} 


\section{INTRODUÇÃO}

O presente trabalho tem por finalidade explicitar aspectos microscópicos relevantes da movimentação dentária induzida em murinos quanto aos: (1) diferentes períodos de observação e (2) planos dos cortes microscópicos transversais e longitudinais.

Os estudos experimentais sobre a movimentação dentária induzida em murinos variam quanto aos períodos e planos de cortes microscópicos, mesmo naqueles trabalhos que utilizam especificamente o modelo de Heller e Nanda, de $1979^{14}$. Para contribuir: (1) na escolha do melhor design experimental de movimentação dentária induzida em murinos em futuros trabalhos, e (2) no aperfeiçoamento dos critérios de análise por outros pesquisadores, propusemo-nos a publicar esse artigo.

A utilização de estudos experimentais em animais tem como objetivo verificar as alterações dos tecidos periodontais nos dentes envolvidos e obter o deslocamento dentário. A definição mais apropriada para esse tipo de deslocamento é o movimento dentário induzido ${ }^{6}$.

Os estudos microscópicos pioneiros referentes à movimentação dentária induzida datam de 1901 e 1911, respectivamente, com os trabalhos experimentais de Sandstedt ${ }^{28}$, em cães, e de Oppenheim $^{24}$, em macacos. Nesse período, os autores analisavam as reações biológicas dos tecidos periodontais nos dentes movimentados, simulando o movimento dentário em modelos experimentais.

Até meados da década de 50, poucos trabalhos empregavam roedores em experimentos de movimentação dentária induzida. Cães e macacos eram os animais de escolha nos estudos microscópicos da biologia do movimento dentário induzido. $\mathrm{Na}$ época, justificava-se a utilização desses animais principalmente por razões técnicas, considerando o fato de que o tamanho de seus dentes era mais próximo ao de dentes humanos e, por isso, forças comumente utilizadas na clínica ortodôntica poderiam ser facilmente empregadas nesses experimentos ${ }^{18}$.
Com a evolução nos estudos experimentais, inúmeros trabalhos, senão a maioria destes, empregam ratos no movimento dentário induzido ${ }^{21,22,27,29,33}$. Esses animais oferecem algumas vantagens, dentre elas a manutenção com menor custo - quando comparados aos primatas, gatos e cães - e o emprego em larga escala, devido ao curto período de procriação e ninhadas com vários filhotes ${ }^{27}$.

A biologia da movimentação dentária induzida tem seus aspectos morfológicos microscópicos repetidamente descritos em vários artigos, teses e livros $2,5,7,8,13,14,21,23,25,32,33,35,36$. Ao microscópio óptico, as modificações biológicas são observadas no ligamento periodontal, no osso alveolar e nas raízes dos dentes movimentados. Dentre elas, estão as áreas hialinas do ligamento periodontal, as reabsorções ósseas frontal e à distância e as reabsorções nas raízes dos dentes movimentados. Notam-se, também, alterações morfológicas e quantitativas das células clásticas no ligamento periodontal e em meio ao osso alveolar. No ligamento, essas alterações ocorrem principalmente nas lacunas de Howship, tanto na periferia do osso alveolar quanto na periferia das raízes do dente movimentado. Em meio ao osso, as alterações ocorrem nas lacunas de Howship, no interior dos espaços medulares.

A biologia da movimentação dentária induzida modifica-se por uma série de condicionantes como, por exemplo, a intensidade da força, o tipo do movimento, o período de observação, os dentes envolvidos, a morfologia radicular e da crista óssea, o plano dos cortes microscópicos e a influência de medicamentos ${ }^{9,16,19,20,21,31,34}$.

Considerando as modificações biológicas referentes à movimentação dentária induzida e as condicionantes que alteram a biologia do movimento dentário, empregou-se o modelo experimental em ratos e a análise microscópica qualitativa para avaliar os fenômenos teciduais e celulares do movimento dentário induzido em diferentes períodos de observação e nos planos dos cortes microscópicos transversais e longitudinais. 


\section{MATERIAL E MÉTODOS}

\section{Delineamento experimental: distribuição dos animais}

O estudo empregou 50 ratos machos, albinos, da linhagem Wistar (Rattus norvegicus), com 90 dias de vida, pesando em média 300g. Os animais foram distribuídos considerando-se as duas condicionantes avaliadas (período de observação e plano de cortes microscópicos), como mostra o quadro 1.

\begin{tabular}{ccc} 
períodos/cortes & transversal & longitudinal \\
0 & 5 & 5 \\
3 & 5 & 5 \\
5 & 5 & 5 \\
7 & 5 & 5 \\
9 & 5 & 5 \\
TOTAL & 25 & 25 \\
\hline
\end{tabular}

Quadro 1 - Distribuição dos animais por período de observação $(0,3,5,7$ e 9 dias) e plano dos cortes microscópicos (transversal e longitudinal).

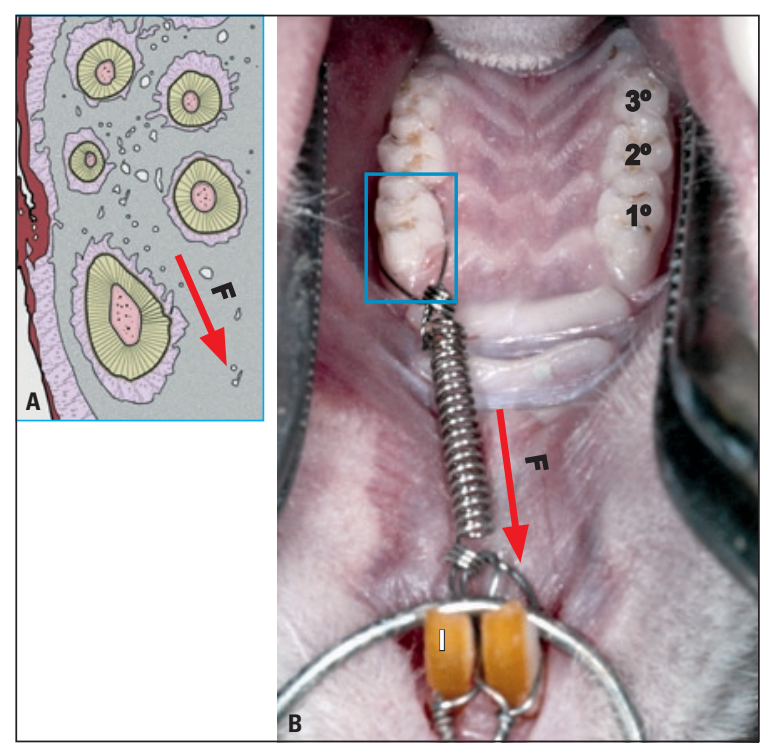

FIGURA 1 - A) Esquema de corte transversal das raízes do primeiro molar superior esquerdo. B) Dispositivo ortodôntico instalado para a inclinação mesial do primeiro molar superior esquerdo, ancorado nos incisivos superiores, despendendo uma força de $75 \mathrm{cN}$. Observam-se a direção da força (seta); os primeiro, segundo e terceiro molares superiores $\left(1^{\circ}, 2^{\circ}\right.$ e $\left.3^{\circ}\right)$; e o incisivo (I).

\section{Delineamento experimental: aparelho e intensidade de força}

Utilizou-se inclinação mesial do primeiro molar superior esquerdo, empregando um dispositivo ortodôntico construído de acordo com Heller e Nanda ${ }^{14}$, em 1979, e modificado por MartinsOrtiz $^{21}$, em 2004.

O design do aparelho constituiu-se de uma mola de aço inoxidável fechada de $4 \mathrm{~mm}$ de comprimento. Essa mola foi amarrada no primeiro molar superior esquerdo com fio de amarrilho de $0,14 \mathrm{~mm}$ de diâmetro e, então, distendida $2 \mathrm{~mm}$, despendendo uma força de $75 \mathrm{cN}$ sobre o primeiro molar superior esquerdo, medida e padronizada previamente com dinamômetro ortodôntico. Em seguida, a mola foi amarrada aos incisivos superiores com fio de amarrilho de $0,25 \mathrm{~mm}$ de diâmetro (Fig. 1). Os incisivos e o fio de amarrilho foram protegidos com resina composta quimicamente ativada de uso ortodôntico.

\section{Delineamento experimental: dente movimentado}

O primeiro molar superior do rato pode apresentar de 4 a 6 raízes, na maioria das vezes cinco raízes, denominadas: mesiovestibular (MV), mesiolingual (ML), intermediária vestibular (INT), distovestibular (DV) e distolingual (DL) (Fig. 2). Considerando a presença das raízes, pode-se classificar a mesiovestibular, a distovestibular e a distolingual como raízes estáveis, enquanto a mesiolingual e a intermediária como raízes instáveis. A raiz mesiolingual geralmente está ausente nos molares com quatro raízes, enquanto nos molares de seis raízes uma segunda raiz intermediária está presente na lingual.

A forma e o volume das raízes desse dente variam entre si. As raízes mesiais são maiores e mais volumosas que as distais (Fig. 2). Além disso, a forma das raízes, se analisadas longitudinalmente ao longo do terço cervical, médio e apical, é semelhante a uma clava (especialmente a mesiovestibular) (Fig. 3). Isso decorre da grande deposição 


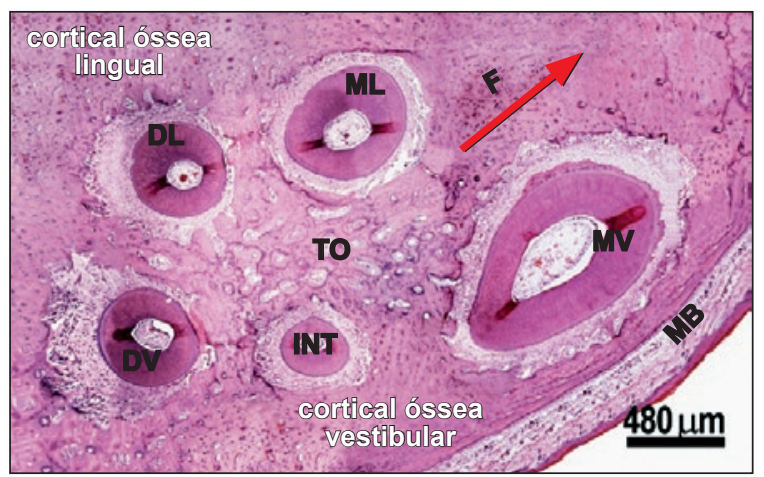

FIGURA 2 - Corte transversal do primeiro molar superior com 5 dias de movimentação dentária induzida. Observam-se as raízes mesiovestibular (MV), mesiolingual (ML), intermediária vestibular (INT), distovestibular (DV) e distolingual (DL). Nota-se que as raízes mesiais são mais volumosas que as distais. Observam-se a direção da força (seta), a cortical óssea vestibular e a cortical óssea lingual (MB: mucosa bucal; T0: trabeculado ósseo).

de cemento no terço apical dessas raízes.

Em cortes longitudinais, o primeiro molar superior do rato tem a forma semelhante a um trapézio, formado pelas retas tangentes às faces mesial e distal, mais as retas tangentes aos ápices e às cúspides deste dente.

Em cortes transversais, esse dente também se apresenta com a forma de um trapézio. Nesse caso, essa figura geométrica é formada pelas retas vestibular (tangente à face vestibular das raízes mesiovestibular, intermediária e distovestibular), lingual (tangente à face lingual das raízes distolingual, mesiolingual e intermediária, quando presente), mesial (tangente à face mesial das raízes mesiovestibular e mesiolingual) e distal (tangente à face distal das raízes distovestibular e distolingual).

\section{Delineamento experimental: critérios qualitativos morfológicos para a análise microscópica}

Os aspectos microscópicos da movimentação dentária induzida foram analisados no ligamento periodontal, no osso alveolar e nas raízes do

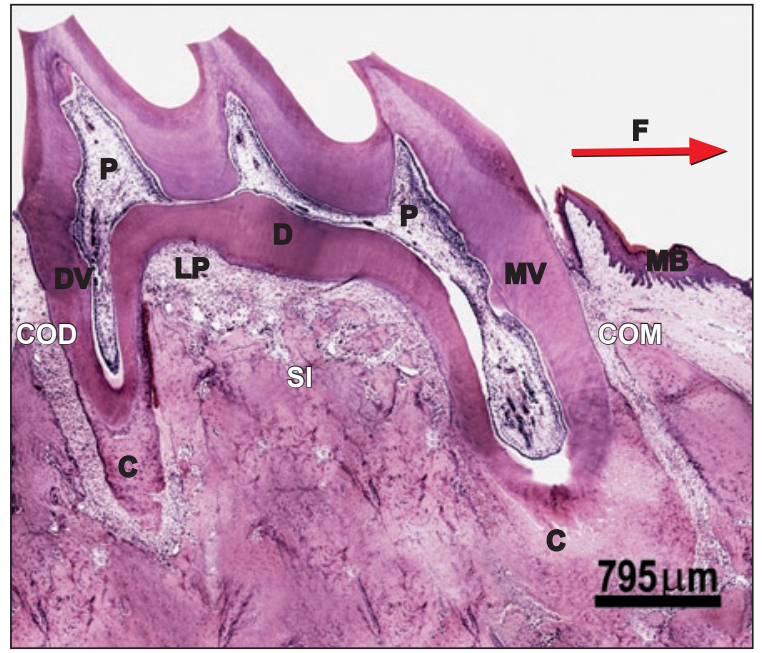

FIGURA 3 - Corte longitudinal do primeiro molar superior com 5 dias de movimentação dentária induzida. Observam-se as raízes mesiovestibular (MV) e distovestibular (DV). Notam-se o formato de clava da raiz mesiovestibular e a exuberante espessura do cemento (C) no terço apical. Observa-se a direção da força (seta) (P: polpa; D: dentina; LP: ligamento periodontal; MB: mucosa bucal; COM: crista óssea mesial; COD: crista óssea distal; SI: septo inter-radicular).

primeiro molar, nos lados de pressão e tensão.

Nos cortes longitudinais, a análise ocorreu nas raízes mesiovestibular e distovestibular. Nos cortes transversais, a análise ocorreu nas raízes mesiovestibular (MV), mesiolingual (ML), intermediárias (INT), distovestibular (DV) e distolingual (DL).

A avaliação microscópica empregada foi qualitativa e consideraram-se os fenômenos teciduais e celulares decorrentes do movimento dentário induzido. Dentre esses fenômenos estão:

a) áreas hialinas do ligamento periodontal;

b) células clásticas;

c) reabsorção óssea frontal;

d) reabsorção óssea à distância;

e) reabsorção radicular;

f) distensão das fibras do ligamento periodontal.

\section{Áreas hialinas do ligamento periodontal}

A força aplicada no dente durante a movimentação dentária induzida comprime os vasos do ligamento periodontal, gera hipóxia ${ }^{10}$ e, conseqüentemente, fuga e/ou morte celular. A matriz extracelular altera a relação bioquímica e 
organizacional dos seus componentes (peptideoglicanas, glicoproteínas, fibras colágenas e elásticas), resultando em áreas de maior concentração protéica, com união de densos feixes de fibras colágenas. Isso resulta em áreas microscopicamente pobres em células e de aspecto eosinofílico homogêneo (fosco, do tipo vidro despolido), denominadas áreas hialinas da matriz extracelular (Fig. 4).

\section{Células clásticas}

A força aplicada para a movimentação dentária induzida comprime os vasos da microcirculação local, gera hipóxia e, conseqüentemente, morte celular $^{10}$. Na morte celular, há desintegração celular e tecidual, gerando especialmente proteínas livres, que desencadearão fenômenos vásculo-exsudativos próprios do processo inflamatório. Os elementos plasmáticos derivados do exsudato inflamatório, principalmente, os derivados do ácido araquidônico, citocinas e fatores de crescimento induzirão a osteoclasia no local.

A presença da plasmina induz os osteoblastos justapostos na superfície óssea alveolar a produzir colagenases. Essas enzimas irão digerir o tecido osteóide que protege a superfície óssea. Conseqüentemente, os cristais de hidroxiapatita ficarão expostos e exercerão efeito quimiotático para as células clásticas, que irão se instalar na superfície óssea desnuda. Essas células podem ser mononucleadas e multinucleadas ${ }^{26}$. As células clásticas multinucleadas têm em média sete núcleos, podendo apresentar até 15 núcleos e, geralmente, apresentam-se microscopicamente próximas a vasos sanguíneos (Fig. 5).

Simultaneamente, os produtos do ácido araquidônico, em especial a prostaglandina E2, interagem com os receptores de membrana dos osteoblastos na superfície óssea e induzem a contração do citoesqueleto dessas células ${ }^{11}$. A redução do volume dos osteoblastos abre espaços entre essas células e expõe o tecido osteóide que recobre a superfície óssea ao meio tecidual. O tecido exposto é envolvido pelo exsudato e infiltrado inflamatório, rico em enzimas proteolíticas. As condições
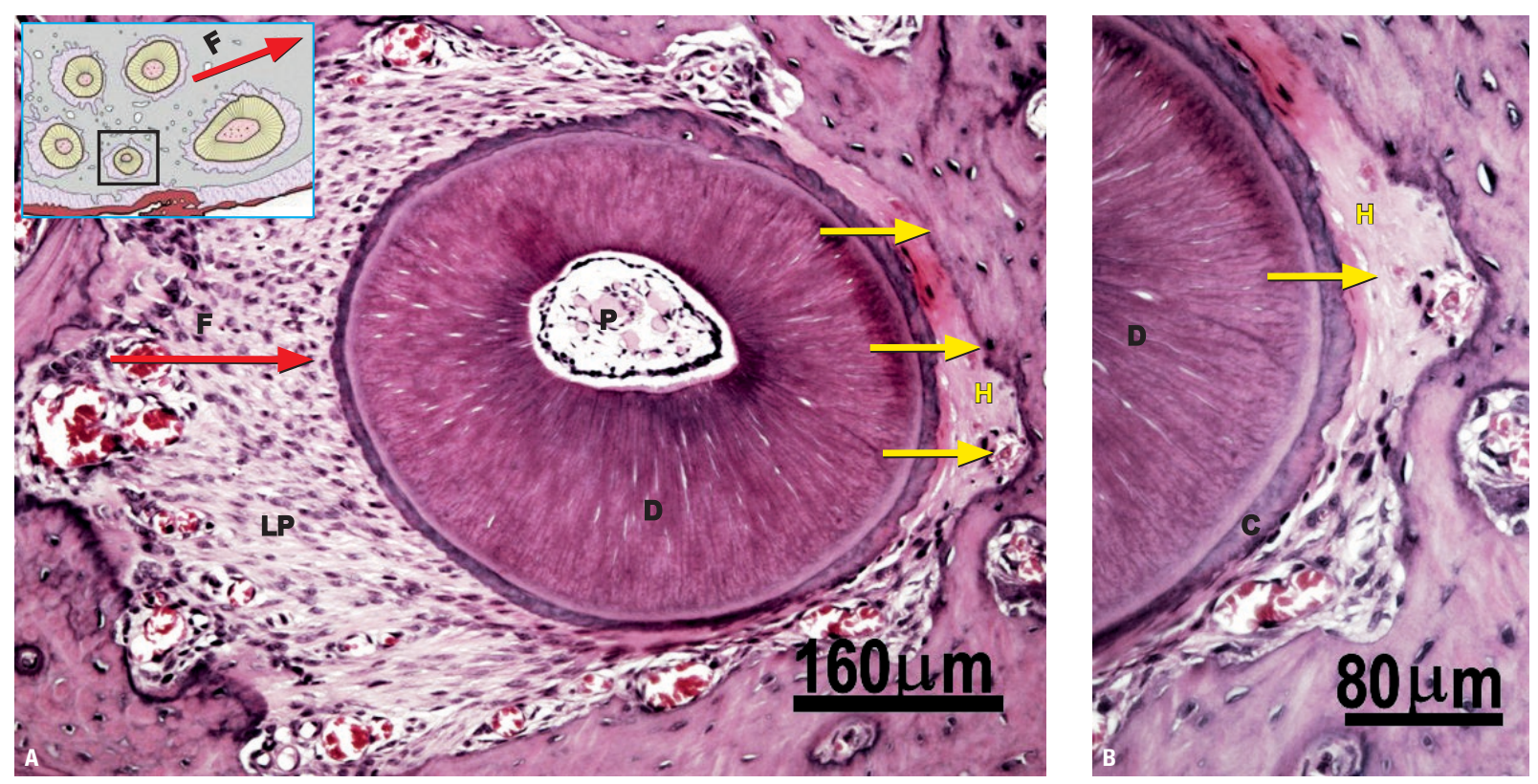

FIGURA 4 - Corte transversal de raiz intermediária do primeiro molar superior com 3 dias de movimentação dentária induzida. A) Nota-se a direção da força (seta vermeIha). A, B) Área hialina (H) no lado de pressão da raiz intermediária (setas amarelas) (P: polpa; D: dentina; C: cemento; LP: ligamento periodontal). 

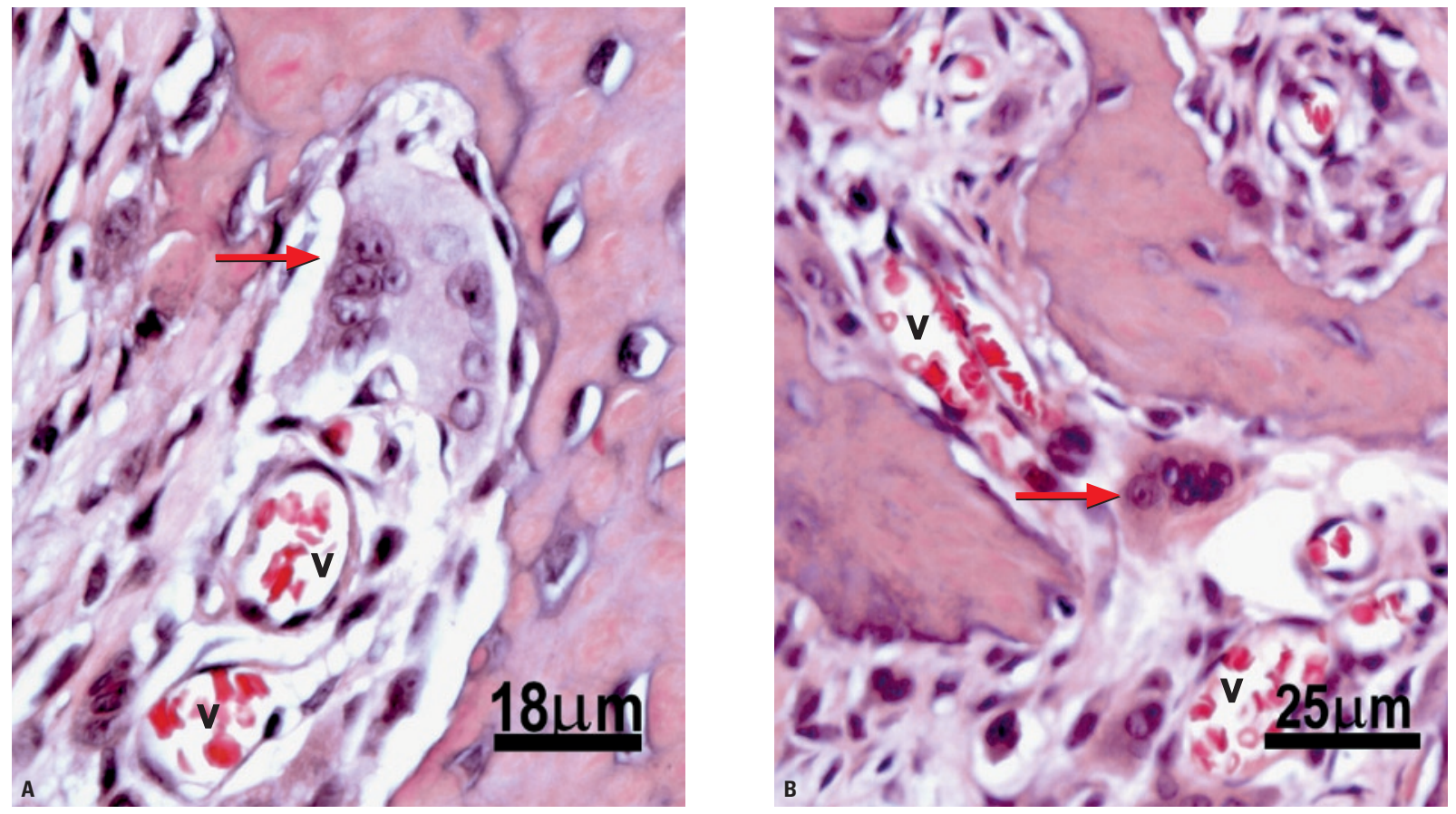

FIGURA 5 - Células clásticas multinucleadas (setas) em (A) com 9 núcleos aparentes e em (B) com 6 núcleos aparentes. As células clásticas apresentam-se próximas a vasos sanguíneos (V).

locais, como o $\mathrm{pH}$ ácido, levam ao deslocamento dos osteoblastos da superfície óssea.

Dessa maneira, a associação da colagenase liberada pelos osteoblastos com a colagenase do exsudato inflamatório promove a perda de uma extensa área de tecido osteóide, expondo ainda mais a superfície óssea à ação das células clásticas e promovendo, indiretamente, efeito quimiotático para essas células, devido à exposição dos cristais de hidroxiapatita.

Além disso, os produtos derivados do exsudato inflamatório, como citocinas, fatores de crescimento e prostaglandinas, interagem nos receptores específicos na membrana dos osteoblastos e macrófagos. Essa interação induz a mobilização de mais células clásticas para a superfície óssea exposta.

O conjunto celular constituído por células clásticas, osteoblastos e macrófagos constitui as unidades de reabsorção ou osteorremodeladoras (do Inglês Bone Modelling Units - BMUs), responsáveis pela reabsorção do tecido mineralizado ${ }^{1}$.

\section{Reabsorção óssea frontal}

A reabsorção óssea na superfície da cortical alveolar, nas áreas submetidas à pressão, que aparece frontalmente ao local de aplicação da força no ligamento periodontal, pode ser identificada como reabsorção óssea frontal ou direta (Fig. 6). Essa reabsorção ocorre quando a força é moderada e gera o mínimo de áreas hialinas no ligamento periodontal.

$\mathrm{Na}$ reabsorção óssea frontal, não se observam alterações significantes na organização dos cementoblastos da superfície radicular e raramente ocorre exposição do cemento na raiz.

Microscopicamente, há inúmeras lacunas de Howship na periferia da cortical óssea, ora com células clásticas mononucleadas, ora com células clásticas multinucleadas.

\section{Reabsorção óssea à distância}

Quando a força aplicada ao dente é de grande intensidade, pode haver o colabamento dos vasos 


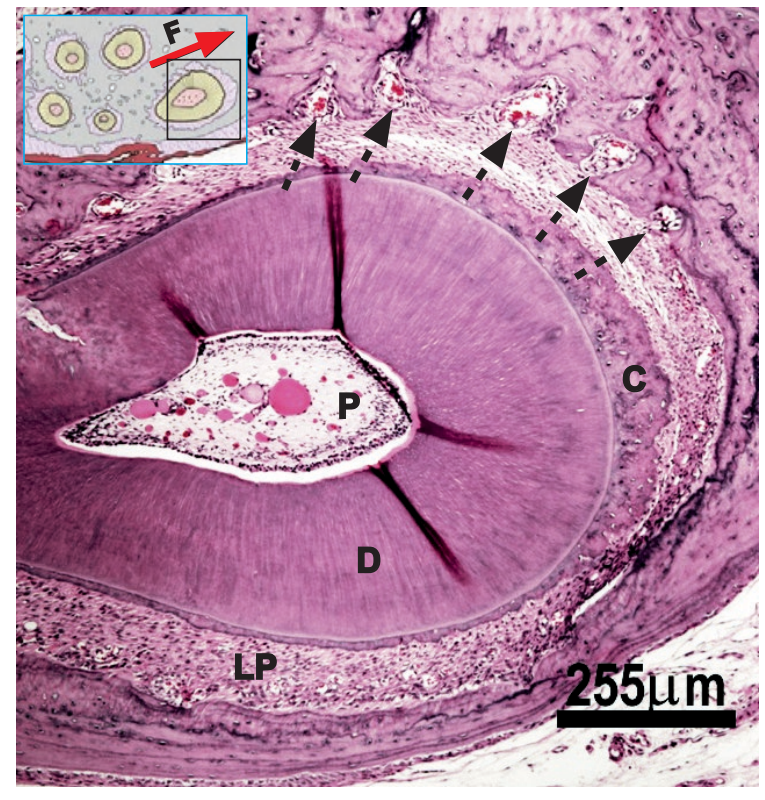

FIGURA 6 - Corte transversal de raiz mesiovestibular do primeiro molar superior com 3 dias de movimentação dentária induzida. Nota-se reabsorção óssea frontal no lado de pressão da raiz (setas) (P: polpa; D: dentina; C: cemento; LP: ligamento periodontal).

sanguíneos do ligamento periodontal e ausência de oxigênio local (anoxia) ${ }^{10}$. Conseqüentemente, ocorrerá morte celular, migração de células e extensas áreas hialinas se formarão no local. A presença de áreas hialinas constitui um fenômeno indesejável, pois atrasa a movimentação dentária induzida. Estes elementos necessitam ser fagocitados antes de haver a reposição celular por novas células migrantes das áreas vizinhas do ligamento periodontal.

A reorganização do ligamento periodontal, e mesmo da superfície óssea alveolar, está diretamente relacionada à atividade dos macrófagos durante a remoção dos restos celulares, em especial da matriz extracelular hialinizada. Durante a fagocitose, os macrófagos liberam citocinas e fatores de crescimento, exercendo quimiotaxia para as células mesenquimais, células endoteliais, fibroblastos e osteoblastos, efetivando também estímulos à proliferação e síntese por parte dessas células.

Os eventos inflamatórios começam a ocorrer ao redor das áreas hialinas, na periferia da área de pressão. As células clásticas iniciam a reabsorção óssea na superfície cortical periférica às áreas hialinas e nos espaços medulares adjacentes a essas áreas hialinas. Essa reabsorção vai solapando a parte óssea em contato com o seguimento hialino. Nesse caso, haverá dissipação e alívio do estresse mecânico, devido à descompressão do ligamento periodontal.

Microscopicamente, inúmeras lacunas de Howship estarão preenchidas por células clásticas, nos espaços medulares do osso alveolar e na cortical óssea, na periferia das áreas hialinas (Fig. 7).

\section{Reabsorção radicular}

Concomitantemente à reabsorção óssea à distância, pode haver reabsorção dentária associada. O excesso de força gera compressão dos vasos sanguíneos do ligamento periodontal e ausência de oxigênio no local, provocando a morte dos cementoblastos. Essas células formam a camada cementoblástica, que reveste a superfície radicular.

A resistência da superfície radicular à reabsorção resulta da propriedade dos cementoblastos não apresentarem, na sua membrana celular, receptores aos mediadores estimuladores da reabsorção óssea $^{17,30}$.

Para que ocorra a reabsorção radicular, previamente deve haver perda da camada cementoblástica. Mediante a isso, a superfície radicular fica desnuda e exposta à ação das células clásticas que respondem aos mediadores da reabsorção.

Microscopicamente, esse fenômeno biológico é identificado pela presença de lacunas de Howship na superfície cementária, podendo atingir a camada dentinária, com presença ou não de células clásticas no interior. A área da superfície radicular no local apresenta perda da camada cementoblástica e exposição direta do tecido cementário e dentinário à ação reabsortiva das células clásticas (Fig. 8). 

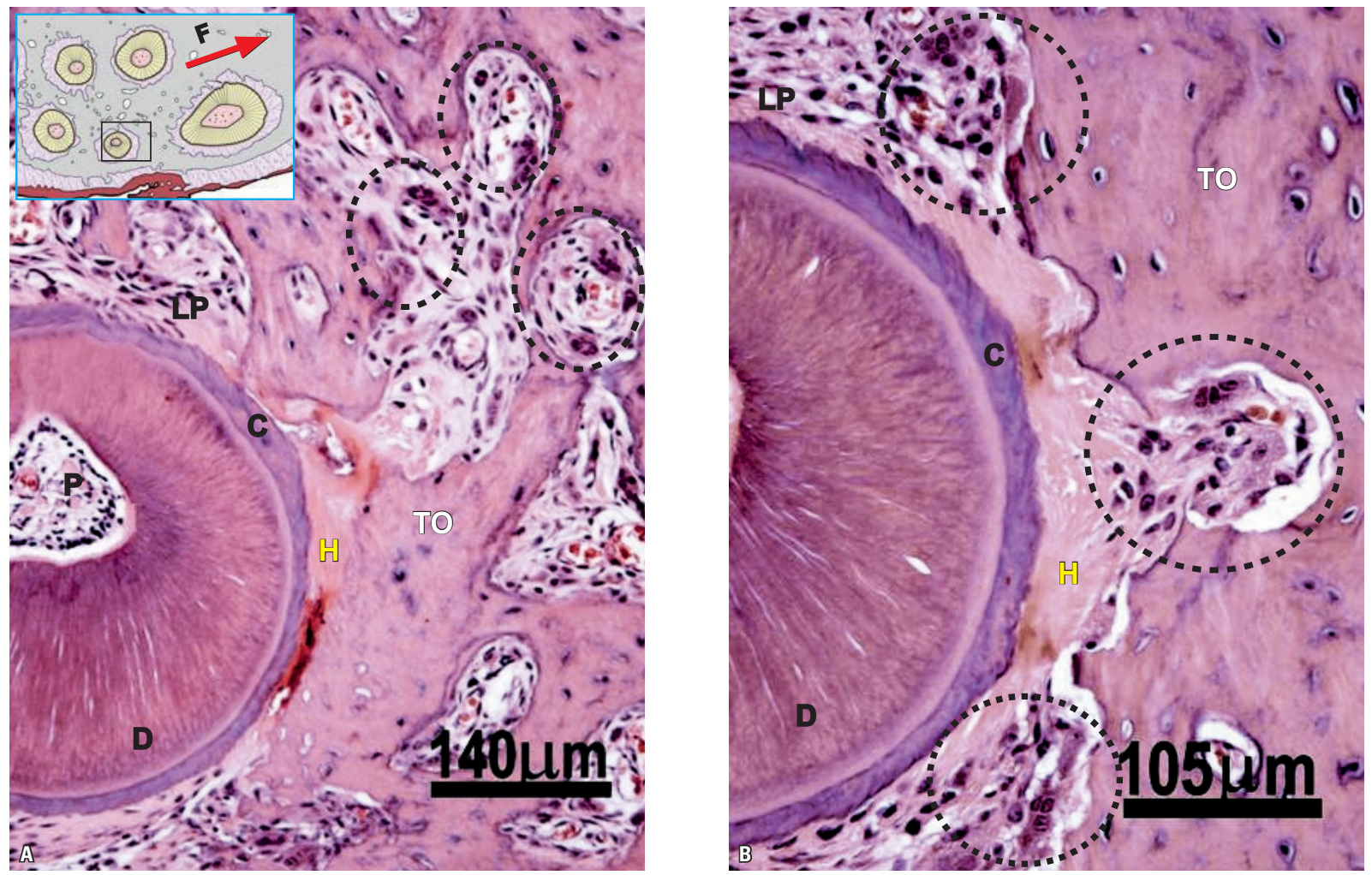

FIGURA 7 - Cortes transversais de raízes intermediárias (lado de pressão) do primeiro molar superior (A) com 5 dias de movimentação dentária induzida e (B) com 7 dias de movimentação dentária induzida. A) Notam-se inúmeras células clásticas nos espaços medulares do osso alveolar (elipses). B) Observam-se células clásticas multinucleadas nas lacunas de Howship na superfície do osso alveolar (elipses), periférica às áreas hialinas (H) (P: polpa; D: dentina; C: cemento; LP: ligamento periodontal; TO: trabeculado ósseo).

Distensão das fibras do ligamento periodontal

As fibras do ligamento periodontal, nos lados de tensão, são estiradas (Fig. 9) e os vasos sanguíneos parcialmente colabados durante a movimentação dentária induzida. As células são discretamente deformadas e se encontram com pequena redução na oxigenação local.

Os mediadores químicos aumentam em pequenos níveis e estimulam a aposição óssea nessas áreas. Microscopicamente, observam-se o aumento da matriz osteóide no lado de tensão e a reinserção das fibras locais.

Mediante forças excessivas, notam-se também áreas de reabsorção radicular e óssea nos locais de estiramento das fibras periodontais. Isso ocorre porque há o rompimento das fibras do ligamento periodontal, aumento nos níveis de mediadores ligados à inflamação e conseqüente desencadeamento dos fenômenos reabsortivos.

\section{Delineamento experimental: períodos de observação}

Os períodos de observação empregados para a movimentação dentária induzida foram de 3, 5, 7 e 9 dias. A análise microscópica qualitativa dessa condicionante foi realizada em cortes transversais e longitudinais. Apesar de estudos pilotos mostrarem que o intervalo de 3 a 7 dias trouxe resultados comparativamente significantes entre as variáveis estudadas, nesse trabalho implementou-se o período de 9 dias, com o objetivo de certificar se nesse período as reabsorções decorrentes do movimento 


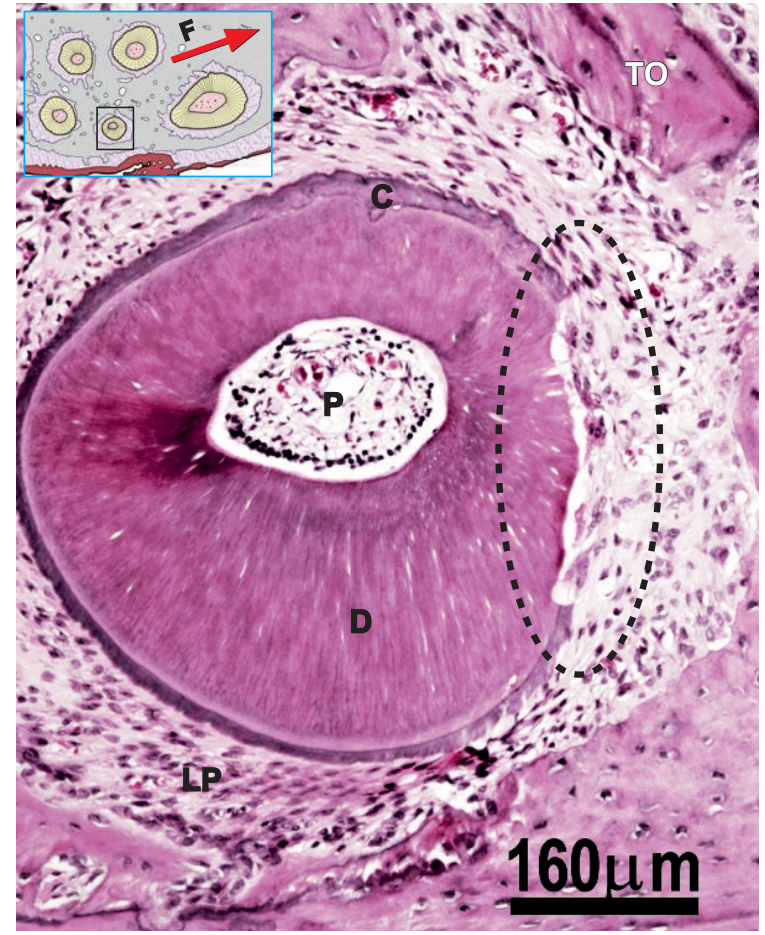

FIGURA 8 - Corte transversal de raiz intermediária do primeiro molar superior com 7 dias de movimentação dentária induzida. Notam-se a reabsorção radicular, a exposição de dentina e a presença de células clásticas na periferia da raiz no lado de pressão (elipse) (P: polpa; D: dentina; C: cemento; LP: ligamento periodontal; TO: trabeculado ósseo).

dentário induzido apresentam-se morfologicamente melhor delineadas, principalmente no que se refere às reabsorções radiculares.

\section{Delineamento experimental: plano dos cortes microscópicos}

Os planos de corte empregados na análise microscópica foram os longitudinais e os transversais. A análise microscópica qualitativa dessa condicionante foi realizada comparando-se os cortes transversais e longitudinais, dentro do mesmo período de observação. Em um único plano de corte longitudinal pôde-se visualizar integralmente apenas duas raízes, em geral, a mesiovestibular (MV) e a distovestibular (DV) $7,21,23,25,32$ (Fig. 3). No entanto, o plano de corte transversal possibilitaria vizualizar todas as raízes do primeiro molar superior simultaneamente (Fig. 2). Essa característica associada à riqueza de detalhes anatômicos das raízes,

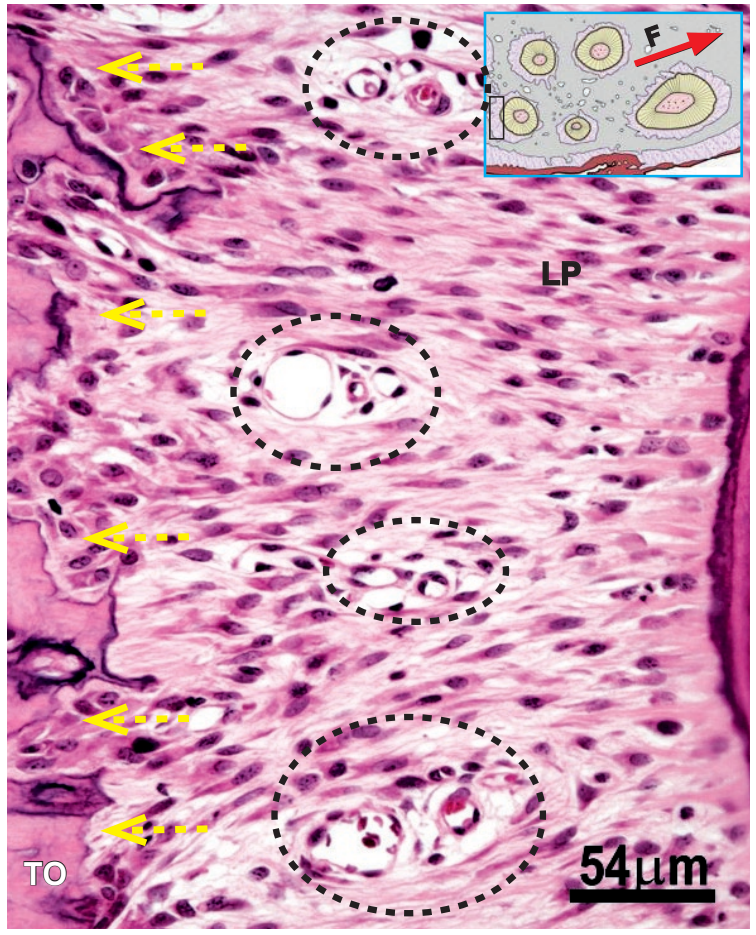

FIGURA 9 - Corte transversal de raiz distovestibular (lado de tensão) do primeiro molar superior com 5 dias de movimentação dentária induzida. Notam-se 0 estiramento das fibras periodontais, os vasos sanguíneos (elipses) e a organização osteoblástica superficial pré-aposição óssea (setas) (LP: ligamento periodontal; TO: trabeculado ósseo).

ligamento periodontal e osso alveolar circunjacente e a maior facilidade de padronização na fase laboratorial dos cortes fazem das secções transversais as ideais para a análise microscópica da movimentação dentária induzida em murinos.

\section{RESULTADOS E DISCUSSÃO}

\section{Sobre o delineamento experimental:} aparelho, intensidade de força e dente movimentado

O emprego de molas fechadas para inclinação mesial do primeiro molar superior possibilitou modificar a posição desse dente no alvéolo, por meio de fenômenos de reabsorção e de aposição óssea no ligamento periodontal. Nesse modelo experimental, o real sentido da força está voltado para anterior, em direção à linha média, já que a ancoragem ocorre nos incisivos. A anatomia local possibilita um movimento dentário com pouca deflexão 
óssea, evitando, por exemplo, fraturas ósseas durante a movimentação. A maior espessura óssea pode explicar a menor deflexão observada durante a movimentação nesse modelo experimental.

A inclinação mesial do primeiro molar superior com ancoragem nos incisivos superiores possibilita um movimento de inclinação efetivo ${ }^{3,14,15,21}$, já que os incisivos apresentam raízes curvas, longas e volumosas. Essas características fazem com que esses dentes possuam uma grande base de implantação óssea, conferindo-lhes boa ancoragem durante a inclinação mesial do primeiro molar.

O primeiro molar do rato é aproximadamente 50 vezes menor que o molar humano ${ }^{27}$. Extrapolando-se essa proporção, uma força de $75 \mathrm{cN}$ em ratos corresponderia a aproximadamente $3.750 \mathrm{cN}$ em humanos. Clinicamente, esta força seria altíssima e provocaria reabsorções exuberantes no osso e nos dentes humanos. Dessa maneira, a força aplicada no experimento não seria ideal para a clínica ortodôntica.

Considerando-se que o objetivo do trabalho é observar os aspectos microscópicos da movimentação dentária induzida com uma força contínua, em um período curto, de 3 a 9 dias, a utilização de uma força de $75 \mathrm{cN}$ para o experimento é pertinente. $\mathrm{O}$ estudo não evitou fenômenos biológicos exuberantes nos tecidos analisados. Ao contrário da clínica, o trabalho necessita da presença desses fenômenos para estudar algumas condicionantes que alteram as características microscópicas dos tecidos.

O dente ideal para o estudo experimental de movimentação dentária induzida em ratos, utilizando-se o movimento de inclinação mesial, é o primeiro molar superior. Esse dente não apresenta rizogênese contínua e suas raízes não estão próximas das raízes dos incisivos superiores murinos. Essas características anatômicas favorecem a movimentação dentária induzida nesse dente e colocam-no em vantagem em relação aos incisivos, que apresentam rizogênese contínua, e aos molares inferiores, que podem sofrer interferência das raízes dos incisivos inferiores durante a inclinação mesial, por estarem muito próximos.

A diferença na forma e no volume das raízes do primeiro molar superior teve influência direta na distribuição da força utilizada no movimento. Nas raízes mesiais, que são maiores e mais volumosas que as distais, os fenômenos biológicos mostraramse moderados. Nas raízes distais, que são menores e menos volumosas, esses fenômenos revelaramse intensos. Portanto, nesse modelo experimental, uma única força aplicada ao dente mostrou, microscopicamente, fenômenos biológicos intensos nas raízes distais e moderados nas raízes mesiais.

Com a aplicação da força, dois lados nas raízes foram mais afetados, o lado mesial da raiz mesiovestibular e o lado mesial da raiz distovestibular. Em ambas as raizes houve maior incidência de força no terço cervical, já que nesse local o volume radicular é menor. Isso ajuda a explicar os fenômenos mais exuberantes encontrados no terço cervical desse dente. No entanto, o maior tamanho da raiz mesiovestibular permite melhor dissipação da força, de maneira que, mesmo na região cervical, os fenômenos biológicos encontrados foram moderados.

As raízes distais deslocaram-se a uma distância maior dentro do alvéolo do que as raízes mesiais. As fibras periodontais, no lado de tensão, mostraram-se marcantemente estiradas, principalmente nos períodos de 5,7 e 9 dias. Isso ocorreu, provavelmente, pelo menor volume das raízes distais e pela maior distância dessas raízes ao local de incidência direta da força. As características anatômicas e a localização das raízes distais ajudam a explicar os fenômenos intensos microscopicamente observados no lado de pressão.

\section{Sobre o delineamento experimental: critérios qualitativos morfológicos para a análise microscópica nos períodos de observação}

Semelhante aos trabalhos de Yokoya, Sasaki e Shibasaki ${ }^{37}$ e Martins-Ortiz ${ }^{21}$, nos molares com 3 dias de movimentação dentária induzida, os fenômenos biológicos mostraram-se menos marcantes 
que nos demais períodos analisados.

Nos molares com 3 e 5 dias de observação, a análise microscópica revelou reabsorção óssea frontal no lado de pressão da raiz mesiovestibular. A superfície do osso alveolar apresentou pequenas lacunas de Howship com células clásticas. Nos molares com 7 e 9 dias, a superfície óssea periodontal no lado de pressão da raiz mesiovestibular mostrou lacunas sem células clásticas e reparadas por neoformação da matriz óssea.

Nos molares com 3 dias de movimentação, observaram-se áreas hialinas no ligamento periodontal e discreta reabsorção óssea à distância no lado de pressão das raízes intermediária, distovestibular e distolingual. Além disso, notou-se ligeiro estiramento das fibras periodontais no lado de tensão, em todas as raízes. Não se observaram áreas de reabsorção nas raízes analisadas no período de 3 dias.

Nos molares com 5 dias de movimentação, os fenômenos observados mostraram-se semelhantes aos do período de 3 dias, porém mais evidentes, principalmente no que se referia às áreas hialinas. Dos cinco molares analisados neste período, apenas dois apresentaram áreas pontuais e discretas de reabsorção radicular.

Conforme os trabalhos de Hamaya et al. ${ }^{12} \mathrm{e}$ Martins-Ortiz ${ }^{21}$, aos 7 dias, as áreas hialinas mostraram-se reduzidas (Fig. 10B) e em franco processo de fagocitose pelos macrófagos, células da linhagem hematopoiética responsáveis pela remoção do tecido hialinizado ${ }^{4}$. Essas áreas foram observadas no lado de pressão das raízes intermediária, distovestibular e distolingual, em todos os molares
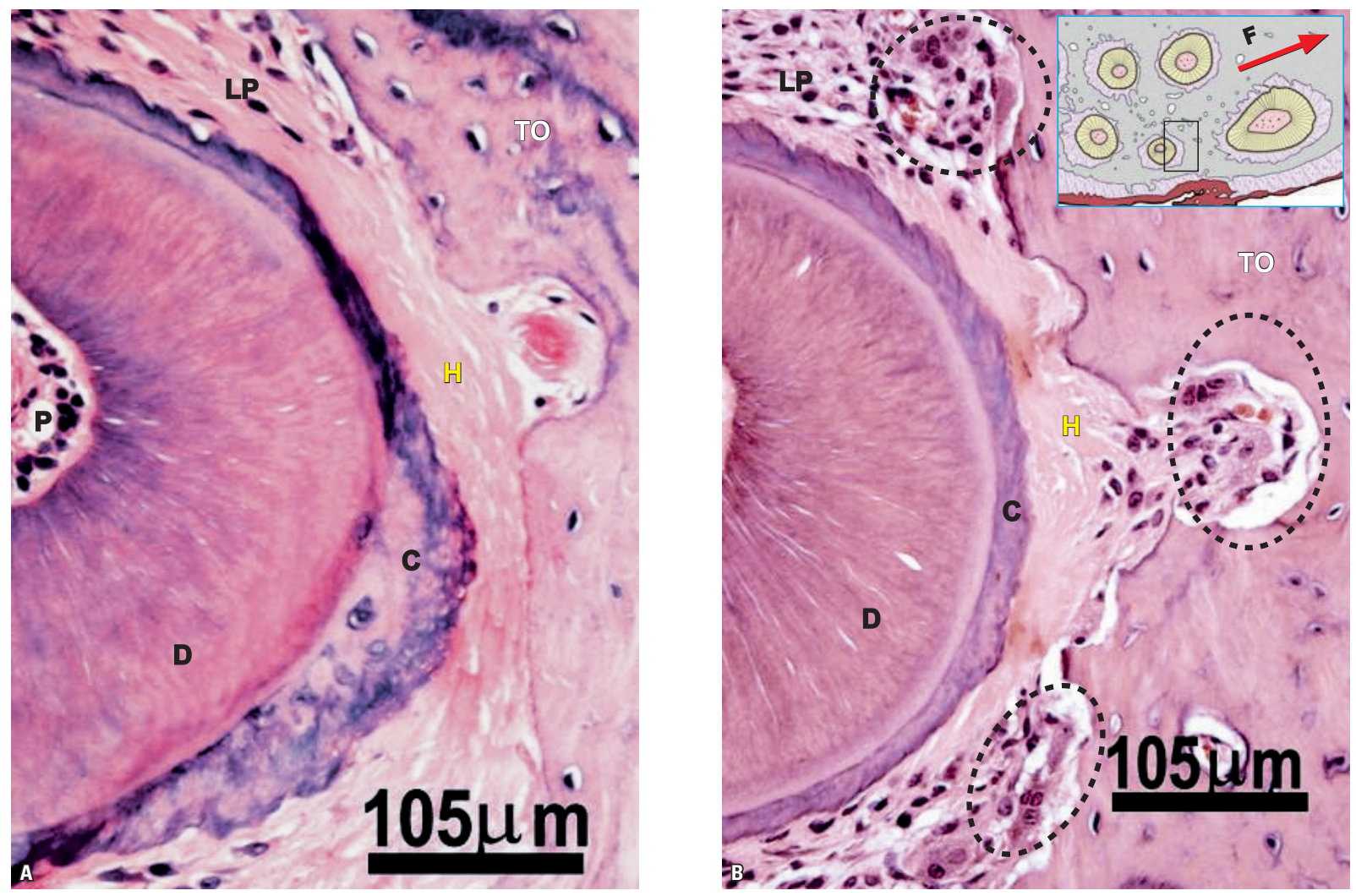

FIGURA 10 - Cortes transversais de raízes intermediárias (lado de pressão) do primeiro molar superior: (A) com 5 dias de observação e (B) com 7 dias de observação. Em (A) observa-se maior área hialina (H) que em (B). Em (B) notam-se lacunas de Howship com células clásticas multinucleadas (elipses) (P: polpa; $\mathbf{D}$ : dentina; C: cemento; LP: ligamento periodontal; TO: trabeculado ósseo). 
analisados neste período. Semelhante a Martins$\mathrm{Ortiz}^{21}$, as células clásticas apresentaram-se nas lacunas de Howship da cortical óssea alveolar, na periferia das áreas de hialinização ${ }^{4}$ (Fig. 10B). Esse fenômeno ocorreu no lado de pressão das raízes intermediária, distovestibular, distolingual e caracterizou uma acentuada reabsorção óssea à distância, em todos os molares analisados. Nessas mesmas raízes, as reabsorções revelaram-se marcantes no lado de pressão. Dos cinco molares analisados, dois não mostraram células clásticas no interior das lacunas de Howship nas áreas de reabsorção radicular. Nesse período, notou-se acentuado estiramento das fibras periodontais, no lado de tensão em todas as raízes analisadas.

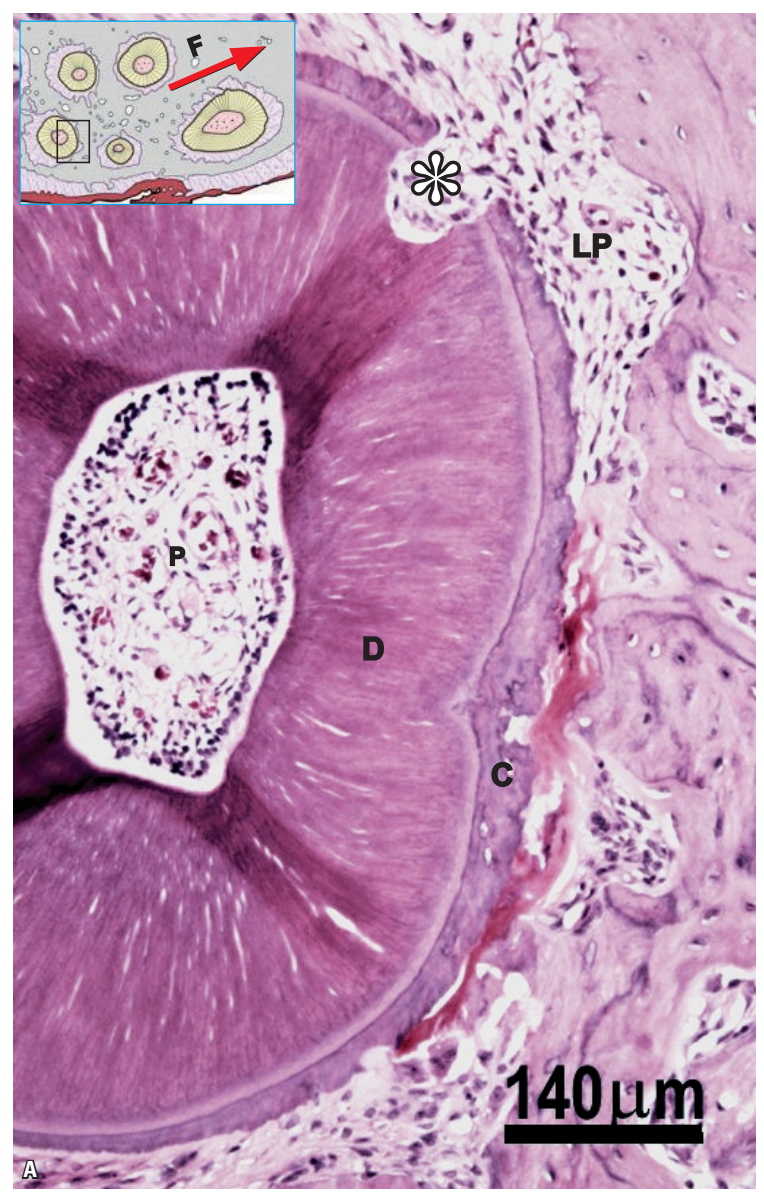

Nos molares com 9 dias de movimentação, os achados microscópicos foram semelhantes aos de 7 dias, com destaque para as reabsorções radiculares, que se mostraram mais exuberantes e bem demarcadas (Fig. 11B).

Os fenômenos biológicos que sofreram maiores variações entre os períodos de observação foram as áreas hialinas do ligamento periodontal e as reabsorções radiculares, ambas no lado de pressão. As áreas hialinas tiveram expressão máxima no período de 5 dias (Fig. 10) e as reabsorções radiculares apresentaram-se exuberantes e bem demarcadas no período de 9 dias (Fig. 11). Nos dois fenômenos, as raízes mais afetadas foram as distais, especialmente a raiz distovestibular.

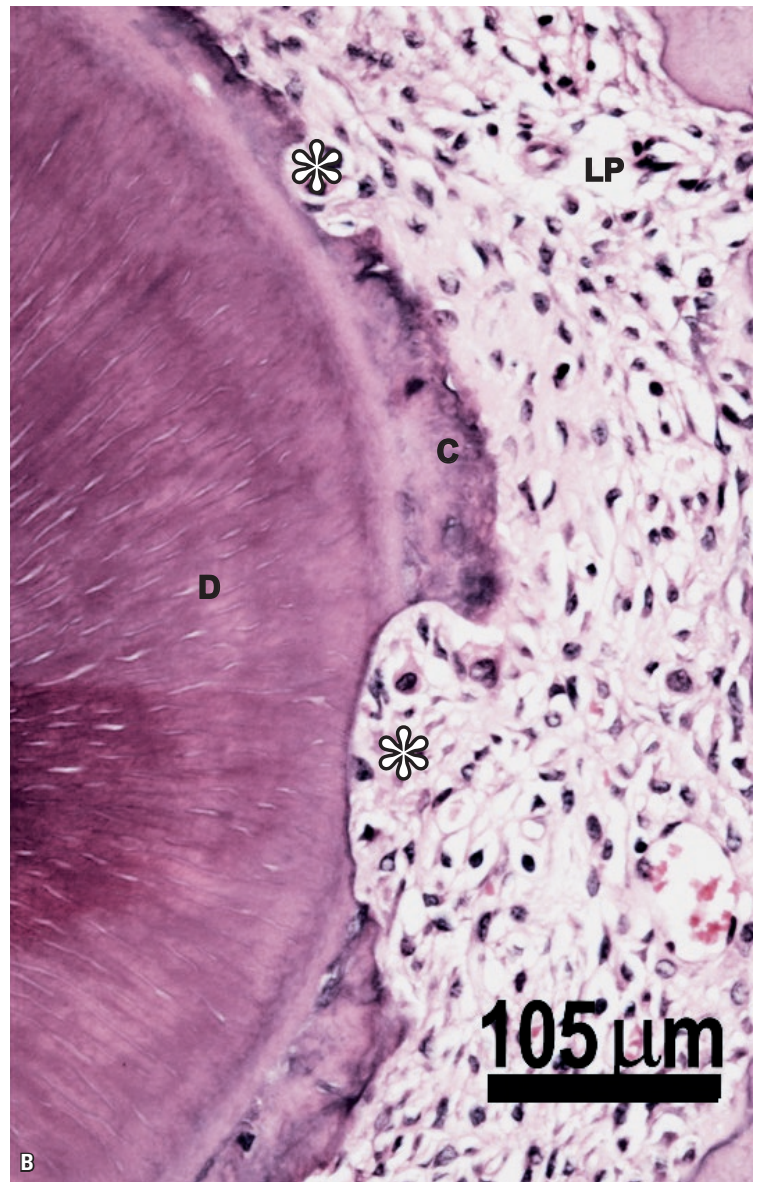

FIGURA 11 - Cortes transversais de raiz distovestibular (lado de pressão) do primeiro molar superior: (A) com 7 dias de observação e (B) com 9 dias de observação. Observa-se que a área de reabsorção radicular $\left({ }^{*}\right)$ em $(\mathbf{B})$ apresenta-se mais exuberante que em (A). 
Sobre o delineamento experimental: critérios qualitativos morfológicos para a análise microscópica nos planos dos cortes microscópicos

Os cortes longitudinais revelaram o longo eixo das raízes mesiovestibular e distovestibular. Não foi possível visualizar mais que duas raízes nesse corte. Em uma única secção, pôde-se notar o volume das raízes mesiovestibular e/ou distovestibular no sentido ocluso-apical. Nesse sentido, pôde-se também observar o ligamento periodontal e o osso alveolar.

Os cortes transversais revelaram a circunferência e o volume de todas as raízes do primeiro molar superior. Nesse corte, obteve-se a relação de todas as raízes com o ligamento periodontal e o osso alveolar.

A análise microscópica comparativa dos cortes transversais e longitudinais foi realizada nas raízes mesiovestibular e distovestibular, já que em cortes longitudinais somente essas raízes estavam presentes.

A análise comparativa da raiz distovestibular mostrou, em secções longitudinais, áreas hialinas mais extensas no longo eixo da raiz, principalmente nos terços cervical e médio. Em cortes transversais, este fenômeno biológico apresentou-se de maneira expressiva no perímetro da raiz distovestibular, ao longo da circunferência dessa raiz.

A análise comparativa na raiz distovestibular também revelou, em cortes transversais, áreas mais extensas de reabsorção radicular. Esse achado microscópico provavelmente ocorreu porque no terço cervical a força atua mais intensamente e, provavelmente, se distribui por toda circunferência radicular, principalmente do lado de pressão. $O$ corte que permite melhor visualização do perímetro radicular é o transversal.

\section{CONCLUSÃO}

O delineamento dos aspectos microscópicos da movimentação dentária induzida em ratos, considerando as condicionantes avaliadas, permite sugerir, para uso nos próximos trabalhos dessa mesma linha de pesquisa, períodos de observação de 5 a 9 dias, já que, aos 3 dias, os fenômenos mostraram-se discretos e semelhantes aos do período de 5 dias.

Verificou-se que a secção ideal para a análise simultânea das raízes e tecidos periodontais circunjacentes, em ratos, é a transversal. Considerando-se que as reabsorções radiculares são um dos fenômenos de maior interesse no estudo da movimentação dentária induzida, e que esse fenômeno mostrou-se mais exuberante em secções transversais, sugerem-se estas secções como cortes de escolha em trabalhos experimentais desse tipo.

\section{AGRADECIMENTOS}

Este trabalho contou com o apoio da Fundação de Amparo à Pesquisa do Estado de São Paulo (04/12424-0). Agradecemos à histotécnica Sra. Fátima Aparecida Silveira, do serviço de Patologia da Faculdade de Odontologia de Bauru, Universidade de São Paulo. 


\title{
Experimental tooth movement in murines: study period and direction of microscopic sections
}

\begin{abstract}
Aim: This study aims to elucidate the relevant microscopic aspects of induced tooth movement in murines with regard to: (1) different study periods; and (2) transverse and longitudinal directions of microscopic sections. Experimental studies on induced tooth movement in murines use variable study periods and directions of microscopic sections, including those studies that specifically use the model adopted by Heller and Nanda in 1979. This manuscript was prepared in order to contribute to: (1) selection of the best study design for future studies on induced tooth movement in murines, and (2) improve the analysis criteria to be used by other investigators. Methods: The study was conducted on 50 male Wistar rats with 90 days of age, submitted to induced tooth movement for periods of 3, 5, 7 and 9 days. The maxillary left first molar was submitted to mesial inclination by application of $75 \mathrm{cN}$ of force. Qualitative microscopic analysis evaluated the tissue and cellular phenomena secondary to induced tooth movement, at the different study periods and on transverse and longitudinal sections. Results: Among the phenomena investigated, hyaline areas of periodontal ligament were mostly observed at 5 days, and root resorptions were remarkable and well delineated at 9 days. Both phenomena affected mainly the distal roots, especially the distobuccal root. Conclusion: Considering the present objective, study periods of 5 to 9 days and transverse microscopic sections may be suggested for future studies on this subject.
\end{abstract}

Key words: Induced tooth movement. Bone resorption. Root resorption.

\section{REFERÊNCIAS}

1. ARNETT, T. R.; DEMPSTER, D. W. Effect of pH on bone resorption by rat osteoclasts in vitro. Endocrinology, Springfield, v. 119, no. 1, p. 119-124, July 1986

2. ASHIZAWA, Y.; SAHARA, N. Quantitative evaluation of newly formed bone in the alveolar wall surrounding the root during the initial stage of experimental tooth movement in the rat. Arch. Oral Biol., Oxford, v. 43, no. 6, p. 473-484, June 1998.

3. BRIDGES, T. et al. The effect of age on tooth movement and mineral density in the alveolar tissues of the rat. Am. J. Orthod. Dentofacial Orthop., St. Louis, v. 93, no. 3, p. 245-250, Mar. 1988.

4. BRUDVIK, P.; RYGH, P. Non-clast cells start orthodontic root resorption in the periphery of hialinized zones. Eur. J. Orthod. London, v. 15, no. 6, p. 467-480, Dec. 1993.

5. CONSOLARO, A. Biologia da movimentação dentária: princípios básicos aplicados à clínica. In: INTERLANDI, S. (Coord.). Ortodontia: bases para a iniciação. 4. ed. São Paulo: Artes Médicas, 1999. cap. 21, p. 435-449.

6. CONSOLARO, A. Reabsorções dentárias nas especialidades clínicas. 2. ed. Maringá: Dental Press, 2005.

7. CONSOLARO, R. B. Análise do complexo dentinopulpar em dentes submetidos à movimentação dentária induzida em ratos. 2005. 138 f. Dissertação (Mestrado em Odontologia)Faculdade de Odontologia de Bauru, Universidade de São Paulo, Bauru, 2005.

8. CUOGHI O. A. Avaliação dos primeiros momentos da movimentação dentária induzida: estudo microscópico em macacos da espécie Cebus apella. 1996. 138 f. Tese (Doutorado em Odontologia)-Faculdade de Odontologia de Bauru, Universidade de São Paulo, Bauru, 1996.

9. FURQUIM, L. Z. Perfil endocrinológico de pacientes ortodônticos com e sem reabsorções dentárias: correlação com a morfologia radicular e da crista óssea alveolar. 2002. $122 \mathrm{f}$. Tese (Doutorado em Odontologia)-Faculdade de Odontologia de Bauru, Universidade de São Paulo, Bauru, 2002.
10. GAENGLER, P.; MERTE, K. Effects of force application on periodontal blood circulation: a vital microscopic study in rats. J. Periodont. Res., Copenhagen, v. 18, no. 1, p. 86-92, Jan. 1983.

11. GRUBER, H. E. Bone and the immune system. Proc. Soc. Exp. Biol. Med., Malden, v. 197, no. 3, p. 219-225, July 1991.

12. HAMAYA, M. et al. Cell death of osteocytes occurs in rat alveolar bone during experimental tooth movement. Calcif. Tissue Int., v. 70, no. 2, p. 117-126, Feb. 2002

13. HATAI, T. et al. Apoptosis of periodontal ligament cells induced by mechanical stress during tooth movement. Oral Dis., Copenhagen, v. 7, no. 5, p. 287-290, Sept. 2001

14. HELLER, I. J.; NANDA, R. Effect of metabolic alteration of periodontal fiber on orthodontic movement: an experimental study. Am. J. Orthod., St. Louis, v. 75, no. 3, p. 239-257, Mar. 1979

15. KONOO, T. et al. Intermittent force in orthodontic tooth movement. J. Dent. Res., Chicago, v. 80, no. 2, p. 457-460, Feb. 2001

16. KRISHNAN, V.; DAVIDOVITCH, Z. The effect of drugs on orthodontic tooth movement. Orthod. Craniofac. Res., Oxford, v. 9, no. 4, p. 163-171, Nov. 2006.

17. LINDSKOG, S.; BLOMLÖF, L.; HAMMARSTRÖM, L. Cellular colonization of denuded root surfaces in vivo: cell morphology in dentin resorption and cementum repair. J. Clin. Periodontol., Copenhagen, v. 14, no. 7, p. 390-395, Aug. 1987.

18. MACAPANPAN, L. C.; WEINMANN, J. P.; BRODIE, A. G. Early tissue changes following tooth movement in rats. Angle Orthod., Appleton, v. 24, no. 2, p. 79-95, Apr. 1954.

19. MALMGREN, O. et al. Root resorption after orthodontic treatment traumatized teeth. Am. J. Orthod. Dentofacial Orthop., St. Louis, v. 82, no. 6, p. 487-491, Dec. 1982.

20. MALTHA, J. C. et al. Incidence and severity of root resorption in orthodontically moved premolars in dogs. Orthod. Craniofac. Res., Oxford, v. 7, no. 2, p. 115-121, May 2004. 
21. MARTINS-ORTIZ, M. F. Influência dos bisfosfonatos na movimentação dentária induzida, na freqüência e nas dimensões das reabsorções radiculares associadas.

2004. 191 f. Tese (Doutorado Odontologia)-Faculdade de Odontologia de Bauru, Universidade de São Paulo, Bauru, 2004.

22. MAVRAGANI, M.; BRUDVIK, P.; SELVIG, K. A. Orthodontically induced root and alveolar bone resorption: inhibitory effect of systemic doxycycline administration in rats. Eur. J. Orthod. London, v. 27, no. 3, p. 215-225, June 2005.

23. MAZZIEIRO, E. T. Bisfosfonato e movimentação dentária induzida: avaliação microscópica de seus efeitos. 1999. 154 f. Tese (Doutorado em Odontologia) - Faculdade de Odontologia de Bauru, Universidade de São Paulo, Bauru, 1999

24. OPPENHEIM, A. Tissue changes, particularly of the bone incident to tooth movement. Am. J. Orthod., St. Louis, v. 3 no. 2, p. 57-67, Oct. 1911

25. PEREIRA, A. C. Influência da gravidez e dos anticoncepcionais na reabsorção radicular e na remodelação óssea, conseqüente à movimentação dentária induzida: avaliação microscópica. 1995. 141 f. Dissertação (Mestrado em Odontologia)-Faculdade de Odontologia de Bauru, Universidade de São Paulo, Bauru, 1995.

26. PIERCE, A. M.; LINDSKOG, S.; HAMMARSTRÖM, L. et al. Osteoclasts: structure and function. Electron. Microsc. Rev. Oxford, v. 4, no. 1, p. 1-45, 1991.

27. REN, Y.; MALTHA, J. C.; KUIJPERS-JAGTMAN, A. M. The rat as model for orthodontic tooth movement: a critical review and a proposed solution. Eur. J. Orthod., London, v. 26, no. 5, p. 483-490, Oct. 2004.

28. SANDSTEDT, C. Nagra bidrag til tandregleringens teori. Stockholm: P. A. Nordstedt \& Stoner. 1901

29. SANTAMARIA JR., M. et al. Initial changes in pulpal microvasculature during orthodontic tooth movement: a stereological study. Eur. J. Orthod., London, v. 28, no. 3 , p. 217-220, June 2006.
30. TENORIO, T: CRUCHLEY, A.; HUGHES, F. J.

Immunocytochemical investigation of the rat cementoblast phenotype. J. Periodontal Res., Copenhagen, v. 28, no. 6, p. 411-419, Nov. 1993

31. TOMISUKA, R. et al. Histological evaluation of the effects of initially light and gradually increasing force on orthodontic tooth movement. Angle Orthod., Appleton, v. 7, no. 3, p. 410-416, May 2007

32. VASCONCELOS, M. H. F. Análise morfológica comparativa do periodonto de sustentação submetido a forças biologicamente excessivas em ratas adultas sem e sob o uso de anticoncepcionais em ratas prenhas. 1996.

148 f. Dissertação (Mestrado em Odontologia)-Faculdade de Odontologia de Bauru, Universidade de São Paulo, Bauru, 1996.

33. VASCONCELOS, M. H. F. et al. A histological study of tooth movement in rats under contraceptive use. In: DAVIDOVITCH, Z.; MAH, J. (Ed.). Biological mechanisms of tooth eruption resorption and replacement by implants. Boston: Harvard Society or the Advancement of Orthodontics, 1998. p. 539-543.

34. VERNA, C. et al. Influence of steroid drugs on orthodontically induced root resorption. Orthod. Craniofac. Res., Oxford, v. 9, no. 1, p. 57-62, Feb. 2006.

35. VERNA, C.; ZAFFE, D.; SICILIANI, G. Histomorphometric study of bone reactions during orthodontic tooth movement in rats. Bone, Elmsford, v. 24, no. 4, p. 371-379, Apr. 1999.

36. WILLIAMS, S. A histomorphometric study of orthodontically induced root resorption. Eur. J. Orthod., London, v. 6, no. 1, p. 35-47, Feb. 1984.

37. YOKOYA, K.; SASAKI, T.; SHIBASAKI, Y. Distributional changes of osteoclasts and preosteoclasts cells in periodontal tissues during experimental tooth movement as reveled by quantitative immunohistochemistry of H+-ATPase. J. Dent. Res., Chicago, v. 76, no. 1, p. 580-587, Jan. 1997.
Endereço para correspondência

Ana Carolina Cuzzuol Fracalossi

Rua Alameda Dr. Octávio Pinheiro Brisolla, 9-75

CEP: 17.012-901 - Vila Universitária - Bauru/ SP

E-mail: carol_cuzzuol@yahoo.com.br 